\title{
PENERAPAN IMPROVED GENERALIZED VARIANCE PADA PENGENDALIAN KUALITAS PAVING BLOCK SEGIENAM
}

\author{
Nathasa Erdya Kristy ${ }^{1}$, Mustafid ${ }^{2}$, Sudarno ${ }^{3}$ \\ 1,2,3 Departemen Statistika FSM Universitas Diponegoro \\ Email: Mustafid55@gmail.com
}

\begin{abstract}
In quality assurance of hexagonal paving block products, quality control is needed so the products that produced are in accordance with the specified standards. Quality control carried out involves two interconnected quality characteristics, that is thickness and weight of hexagonal paving blocks, so multivariate control chart is used. Improved Generalized Variance control chart is a tool used to control process variability in multivariate manner. Variability needs to be controlled because of in a production process, sometimes there are variabilities that caused by engine problems, operator errors, and deffect in raw materials that affect the process. The purpose of this study is to apply Improved Generalized Variance control chart in controlling the quality of hexagonal paving block products and calculating the capability of production process to meet the standards. Based on the assumption of multivariate normal distribution test, it can be seen that the data of quality characteristics of hexagonal paving blocks have multivariate distribution. While based on the correlation test between variables it can be concluded that the characteristics of the quality of thickness and weight correlate with each other. The result of the control using these control chart shows that the process is statistically in control. The results of process capability analysis show that the production process has been running according to the standard because the process capability index value is generated using a weighting of 0.5 for each quality characteristic that is 1.01517 .
\end{abstract}

Keywords: Paving Block, Quality Control, Variability, Improved Generalized Variance, Process Capability Analysis

\section{PENDAHULUAN}

Dalam menghadapi persaingan bisnis yang semakin kompetitif, para pelaku bisnis dituntut untuk mampu menghasilkan produk yang berkualitas sehingga dapat diterima oleh konsumen. Kualitas merupakan faktor utama sebagai dasar konsumen dalam memutuskan pemilihan produk yang sesuai keinginan, sehingga kualitas merupakan kunci bagi keberhasilan bisnis.

UD. Tegel $\mathrm{K}$ merupakan salah satu pabrik yang memproduksi paving block di Kabupaten Wonogiri. Salah satu jenis paving block yang diproduksi adalah paving block segienam. Dalam mempertahankan kualitas dari produk yang dihasilkan perlu dilakukan pengendalian kualitas. Dalam proses pengendalian kualitas sering digunakan diagram kontrol yang berupa grafik dari hasil suatu proses produksi sehingga dapat diketahui proses dalam keadaan terkendali atau tidak terkendali.

Karakteristik kualitas yang diperhatikan dalam produksi paving block segienam yaitu ketebalan dan berat dari paving block. Karena terdapat dua karakteristik kualitas yang diperhatikan dalam pengendalian kualitas, maka diagram kontrol yang tepat digunakan adalah diagram kontrol multivariat. Dalam suatu proses produksi, sebaik apapun proses tersebut dirancang pasti akan selalu ada variabilitas yang mempengaruhi proses tersebut. Untuk mengatasi permasalahan tersebut maka perlu digunakan diagram kontrol variabilitas. 
Oleh karena itu, dalam penelitian ini dilakukan pengendalian kualitas proses produksi paving block segienam dengan menggunakan diagram kontrol multivariat Improved Generalized Variance dalam mengontrol variabilitas proses.

\section{TINJAUAN PUSTAKA}

\subsection{Paving Block}

Paving block adalah suatu komposisi bahan bangunan yang terbuat dari campuran semen portland atau bahan perekat hidrolis lainnya, air dan agregat dengan atau tanpa bahan tambahan lainnya yang tidak mengurangi mutu beton tersebut ${ }^{[7]}$.

\subsection{Pengendalian Kualitas Statistik}

Pengendalian kualitas merupakan kegiatan-kegiatan untuk memastikan apakah kebijaksanaan dalam hal kualitas atau standar dapat tercermin dalam hasil akhir. Dengan kata lain pengendalian kualitas adalah usaha mempertahankan kualitas dari barang yang dihasilkan, agar sesuai dengan spesifikasi produk yang telah ditetapkan berdasarkan kebijaksanaan pimpinan perusahaan ${ }^{[1]}$. Tujuan pengendalian kualitas adalah:

1. Agar barang hasil produksi dapat mencapai standar kualitas yang ditetapkan.

2. Mengusahakan agar biaya inspeksi dapat menjadi sekecil mungkin.

3. Mengusahakan agar biaya produksi dapat menjadi serendah mungkin.

\subsection{Uji Distribusi Normal Multivariat}

Distribusi normal multivariat merupakan suatu perluasan dari distribusi normal univariat untuk dimensi $\mathrm{p} \geq 2$ dengan variabel-variabel yang dependen ${ }^{[4]}$. variabel $\boldsymbol{x}=\left(x_{1}, x_{2}, \ldots, x_{p}\right)$ dikatakan berdistribusi normal multivariat dengan parameter $\boldsymbol{\mu}$ dan $\boldsymbol{\Sigma}$ jika mempunyai fungsi densitas probabilitas:

$$
f(\boldsymbol{x})=\frac{1}{(2 \pi)^{p / 2}|\Sigma|^{1 / 2}} e^{-\frac{1}{2}(\boldsymbol{x}-\boldsymbol{\mu})^{\prime} \boldsymbol{\Sigma}^{-1}(\boldsymbol{x}-\boldsymbol{\mu})}
$$

Berdasarkan sifat tersebut maka untuk pemeriksaan distribusi multivariat normal dapat dilakukan dengan cara membuat $q-q$ plot dari nilai

dengan

$$
d_{i j k}^{2}=\left(\boldsymbol{x}_{i j k}-\overline{\overline{\boldsymbol{x}}}_{. . k}\right)^{\prime} \boldsymbol{S}^{-1}\left(\boldsymbol{x}_{\boldsymbol{i j k}}-\overline{\overline{\boldsymbol{x}}}_{. . k}\right)
$$

$i=1,2, \ldots, m$ merupakan banyaknya subgrup

$j=1,2, \ldots, n$ merupakan banyaknya observasi

$k=1,2, \ldots, p$ merupakan banyaknya karakteristik kualitas

Berdasarkan pada kriteria tersebut, pemeriksaan distribusi normal multivariat dapat diasumsikan dengan menggunakan hipotesis:

Hipotesis:

$\mathrm{H}_{0}$ : Data berdistribusi normal multivariat.

$\mathrm{H}_{1}$ : Data tidak berdistribusi normal multivariat.

Statistik uji:

$\mathrm{b}=$ banyaknya nilai $d_{i j k}^{2} \leq \chi_{p}^{2}(0,50)$

dengan p merupakan banyaknya karakteristik kualitas.

Kriteria penerimaan:

$\mathrm{H}_{0}$ diterima jika nilai $\mathrm{b} \geq 50 \%$ dari banyaknya data observasi.

Secara visual asumsi distribusi normal multivariat dapat dilakukan dengan melihat persebaran plot pada $q-q$ plot. Adapun prosedur untuk membuat $q-q$ plot sebagai berikut:

1. Menghitung nilai $d_{i j k}^{2}$.

2. Mengurutkan $d_{i j k}^{2}$ dari yang terkecil sampai yang terbesar. 
3. Menentukan nilai $p_{j}=\frac{j-0,5}{n}, j=1,2, \ldots, n$.

4. Menentukan nilai $q_{j}$ dimana $q_{j}=\chi_{p}^{2}\left(\frac{j-0.5}{n}\right)$.

5. Membuat scatterplot $d_{i j k}^{2}$ dengan $q_{j}$ dengan titik koordinat $\left(d_{i j k}^{2} ; \chi_{p}^{2}\left(\frac{j-0.5}{n}\right)\right)$.

Secara visual plot di definisikan berdistribusi normal multivariat apabila plot-plot pada $q-q$ plot menunjukkan pola yang cenderung mengikuti garis lurus.

\subsection{Uji Korelasi Antar Variabel}

Uji yang biasa digunakan untuk menguji dependensi variabel adalah Uji Bartlett yang merupakan metode pengujian yang digunakan untuk mengetahui ada atau tidaknya hubungan antara variabel yang akan diteliti, supaya dapat memberikan keyakinan bahwa sekumpulan data dalam serangkaian analisis berasal dari populasi yang tidak jauh berbeda keragamannya. Variabel $x_{1}, x_{2}, \ldots, x_{p}$ dikatakan bersifat saling bebas (independen) jika matriks korelasi antar variabel membentuk matriks identitas ${ }^{[6]}$. Hipotesis yang digunakan dalam Uji Bartlett adalah:

Hipotesis:

$\mathrm{H}_{0}: \mathbf{R}=\mathbf{I}$ (antar variabel tidak berkorelasi)

$\mathrm{H}_{1}: \mathbf{R} \neq \mathbf{I}$ (antar variabel berkorelasi)

Statistik uji:

dengan:

$$
\chi_{\text {hitung }}^{2}=-\left[n-1-\frac{2 p+5}{6}\right] \ln |R|
$$

$\mathrm{n}$ adalah banyaknya observasi.

p adalah banyaknya variabel.

$\mathbf{R}$ adalah matriks korelasi dari masing-masing variabel.

$|\mathbf{R}|$ adalah determinan matriks korelasi.

I adalah matriks identitas.

$\chi_{\left[\alpha, \frac{1}{2} p(p-1)\right]}^{2}$ adalah nilai quantil dari distribusi chi-square dengan peluang sebesar $\alpha$ dan derajat bebas sebesar $\frac{1}{2} p(p-1)$.

Kriteria penerimaan: $\mathrm{H}_{0}$ ditolak jika nilai $\chi^{2}$ hitung $>\chi^{2}\left[\alpha, \frac{1}{2} p(p-1)\right]$.

\subsection{Diagram Kontrol Variabel}

Diagram kontrol variabel merupakan diagram kontrol yang digunakan untuk memonitoring suatu karakteristik kualitas yang dapat diukur dan dinyatakan dalam bilangan. Suatu karakteristik kualitas yang dapat diukur menggunakan alat pengukuran tertentu seperti dimensi, berat atau volume dinamakan variabel ${ }^{[5]}$. Berikut ini merupakan struktur data yang sering digunakan untuk diagram kontrol variabel dengan pengamatan multivariat dan data berbentuk subgrup yang dapat dilihat pada Tabel 1.

Tabel 1. Struktur Data Multivariat untuk Pengamatan Subgrup

\begin{tabular}{|c|c|c|c|c|c|c|c|}
\hline \multirow{2}{*}{ Subgrup (i) } & \multirow{2}{*}{ Sampel (j) } & \multicolumn{7}{|c|}{ Variabel (k) } \\
\cline { 2 - 8 } & & $x_{1}$ & $x_{2}$ & $\ldots$ & $x_{k}$ & $\ldots$ & $x_{p}$ \\
\hline \multirow{3}{*}{1} & 1 & $x_{111}$ & $x_{112}$ & $\ldots$ & $x_{11 k}$ & $\ldots$ & $x_{11 p}$ \\
\cline { 2 - 8 } & 2 & $x_{121}$ & $x_{122}$ & $\ldots$ & $x_{12 k}$ & $\ldots$ & $x_{12 p}$ \\
\cline { 2 - 8 } & $\vdots$ & $\vdots$ & $\vdots$ & $\ldots$ & $\vdots$ & $\ldots$ & $\vdots$ \\
\cline { 2 - 8 } & $\mathrm{j}$ & $x_{1 j 1}$ & $x_{1 j 2}$ & $\ldots$ & $x_{1 j k}$ & $\ldots$ & $x_{1 j p}$ \\
\cline { 2 - 8 } & $\vdots$ & $\vdots$ & $\vdots$ & $\ldots$ & $\vdots$ & $\ldots$ & $\vdots$ \\
\hline
\end{tabular}




\begin{tabular}{|c|c|c|c|c|c|c|c|}
\hline & $\mathrm{n}$ & $x_{1 n 1}$ & $x_{1 n 2}$ & $\ldots$ & $x_{1 n k}$ & $\ldots$ & $x_{1 n p}$ \\
\hline & $\bar{x}$ & $\bar{x}_{1.1}$ & $\bar{x}_{1.2}$ & $\ldots$ & $\bar{x}_{1 . k}$ & $\ldots$ & $\bar{x}_{1 . p}$ \\
\hline & $S^{2}$ & $S_{1.1}^{2}$ & $S_{1.2}^{2}$ & $\ldots$ & $S_{1 . k}^{2}$ & $\ldots$ & $S_{1 . p}^{2}$ \\
\hline$\vdots$ & $\vdots$ & $\vdots$ & $\vdots$ & $\ldots$ & $\vdots$ & $\ldots$ & $\vdots$ \\
\hline \multirow{8}{*}{$\mathrm{i}$} & 1 & $x_{i 11}$ & $x_{i 12}$ & $\ldots$ & $x_{i 1 k}$ & $\ldots$ & $x_{i 1 p}$ \\
\hline & 2 & $x_{i 21}$ & $x_{i 22}$ & $\ldots$ & $x_{i 2 k}$ & $\ldots$ & $x_{i 2 p}$ \\
\hline & $\vdots$ & $\vdots$ & $\vdots$ & $\ldots$ & $\vdots$ & $\ldots$ & $\vdots$ \\
\hline & $\mathrm{j}$ & $x_{i j 1}$ & $x_{i j 2}$ & $\ldots$ & $x_{i j k}$ & $\ldots$ & $x_{i j p}$ \\
\hline & $\vdots$ & $\vdots$ & $\vdots$ & $\ldots$ & $\vdots$ & $\ldots$ & $\vdots$ \\
\hline & $\mathrm{n}$ & $x_{i n 1}$ & $x_{i n 2}$ & $\ldots$ & $x_{i n k}$ & $\ldots$ & $x_{i n p}$ \\
\hline & $\bar{x}$ & $\bar{x}_{i .1}$ & $\bar{x}_{i .2}$ & $\ldots$ & $\bar{x}_{i . k}$ & $\ldots$ & $\bar{x}_{i . p}$ \\
\hline & $S^{2}$ & $S_{i .1}^{2}$ & $S_{i .2}^{2}$ & $\ldots$ & $S_{i . k}^{2}$ & $\ldots$ & $S_{i . p}^{2}$ \\
\hline$\vdots$ & $\vdots$ & $\vdots$ & $\vdots$ & $\ldots$ & $\vdots$ & $\ldots$ & $\vdots$ \\
\hline \multirow{8}{*}{$\mathrm{m}$} & 1 & $x_{m 11}$ & $x_{m 12}$ & $\ldots$ & $x_{m 1 k}$ & $\ldots$ & $x_{m 1 p}$ \\
\hline & 2 & $x_{m 21}$ & $x_{m 22}$ & $\ldots$ & $x_{m 2 k}$ & $\ldots$ & $x_{m 2 p}$ \\
\hline & $\vdots$ & $\vdots$ & $\vdots$ & $\ldots$ & $\vdots$ & $\ldots$ & $\vdots$ \\
\hline & $\mathrm{j}$ & $x_{m j 1}$ & $x_{m j 2}$ & $\ldots$ & $x_{m j k}$ & $\ldots$ & $x_{m j p}$ \\
\hline & $\vdots$ & $\vdots$ & $\vdots$ & $\ldots$ & $\vdots$ & $\ldots$ & $\vdots$ \\
\hline & $\mathrm{n}$ & $x_{m n 1}$ & $x_{m n 2}$ & $\ldots$ & $x_{m n k}$ & $\ldots$ & $x_{m n p}$ \\
\hline & $\bar{X}$ & $\bar{x}_{m .1}$ & $\bar{x}_{m .2}$ & $\ldots$ & $\bar{x}_{m . k}$ & $\ldots$ & $\bar{x}_{m . p}$ \\
\hline & $S^{2}$ & $S_{m .1}^{2}$ & $S_{m .2}^{2}$ & $\ldots$ & $S_{m . k}^{2}$ & $\ldots$ & $S_{m . p}^{2}$ \\
\hline \multicolumn{2}{|c|}{$\begin{array}{l}\text { Rata-rata Keseluruhan } \\
\text { Pengamatan }\end{array}$} & $\overline{\bar{x}}_{. .1}$ & $\overline{\bar{x}}_{. .2}$ & $\ldots$ & $\overline{\bar{x}}_{. . k}$ & $\ldots$ & $\overline{\bar{x}}_{. . p}$ \\
\hline \multicolumn{2}{|c|}{$\begin{array}{c}\text { Varian Keseluruhan } \\
\text { Pengamatan }\end{array}$} & $S_{. .1}^{2}$ & $S_{. .2}^{2}$ & $\ldots$ & $S_{. . k}^{2}$ & $\ldots$ & $S_{. . p}^{2}$ \\
\hline
\end{tabular}

Karena dalam penelitian ini datanya memiliki satuan ukur yang berbeda, maka data asli perlu dilakukan transformasi (standarisasi) sebelum dilakukan pemodelan. Tujuan dilakukannya standarisasi untuk menyeragamkan data, jadi nilai standar tidak lagi tergantung pada satuan pengukuran melainkan menjadi nilai baku. Adapun rumus yang digunakan untuk menghitung nilai z-score adalah sebagai berikut:

$$
Z_{i j k}=\frac{\left(X_{i j k}-\overline{\bar{X}}_{. . k}\right)}{S D_{k}}
$$

\subsection{Diagram Kontrol Improved Generalized Variance $(|\mathrm{S}|)$}

Diagram kontrol Improved Generalized Variance merupakan pengembangan dari diagram kontrol Generalized Variance ${ }^{[2]}$. Misalkan $x_{1}, x_{2}, \ldots, x_{p}$ adalah sampel random dari distribusi normal p-variat $\operatorname{Np}(\mu, \boldsymbol{\Sigma})$, dimana matriks kovarian $\boldsymbol{\Sigma}$ adalah definit positif. Maka determinan dari matriks kovarian $|\mathbf{S}|$ berdistribusi

$$
|\mathbf{S}| \sim\left[\frac{|\boldsymbol{\Sigma}|}{(n-1)^{p}}\right] \prod_{k=1}^{p} \boldsymbol{V}_{\boldsymbol{k}}
$$

dimana $\boldsymbol{V}_{\boldsymbol{k}}$ merupakan variabel acak yang independen dan $\boldsymbol{V}_{\boldsymbol{k}}$ mendekati distribusi $\chi_{n-k}^{2}$ dengan $\mathrm{k}=1,2, \ldots$, p. Parameter $\boldsymbol{\Sigma}$ dapat ditaksir berdasarkan persamaan berikut:

$$
\begin{gathered}
E(|\boldsymbol{S}|)=E\left(\frac{|\boldsymbol{\Sigma}|}{(n-1)^{p}} \prod_{k=1}^{p} \boldsymbol{V}_{\boldsymbol{k}}\right) \\
=\frac{|\Sigma|}{(n-1)^{p}} \prod_{k=1}^{p}(n-k)
\end{gathered}
$$


dan

$$
\operatorname{Var}(|\boldsymbol{S}|)=\frac{|\Sigma|^{2}}{(n-1)^{2 p}} \prod_{k=1}^{p}(n-k)\left(\prod_{k=1}^{p}(n-k+2)-\prod_{k=1}^{p}(n-k)\right)
$$

sehingga diperoleh $E(|\boldsymbol{S}|)=b_{1}|\boldsymbol{\Sigma}|$ dan $\operatorname{Var}(|\boldsymbol{S}|)=b_{2}|\boldsymbol{\Sigma}|^{2}$. Oleh karena itu, dalam hal ini $\frac{|\boldsymbol{S}|}{b_{1}}$ dan $\frac{|\boldsymbol{S}|^{2}}{\left(b_{1}{ }^{2}+b_{2}\right)}$ merupakan estimator tak bias dari $|\boldsymbol{\Sigma}|$ dan $|\boldsymbol{\Sigma}|^{2}$. Dengan syarat pengamatannya bersifat sampel tunggal (tidak ada subgrup), dengan

$$
\begin{gathered}
b_{1}=\frac{1}{(n-1)^{p}} \prod_{k=1}^{p}(n-k) \\
b_{2}=\frac{1}{(n-1)^{2 p}} \prod_{k=1}^{p}(n-k)\left(\prod_{k=1}^{p}(n-k+2)-\prod_{k=1}^{p}(n-k)\right)
\end{gathered}
$$

Sedangkan untuk pengamatan yang melibatkan $m$ buah subgrup independen, untuk setiap subgrup dibentuk matriks varian-kovarian $\boldsymbol{S}_{\boldsymbol{i}}$. Dari matriks varian-kovarian tersebut kemudian digunakan untuk mencari matriks $\overline{\boldsymbol{S}}$ dengan rumus $\quad \overline{\boldsymbol{S}}=\frac{1}{m}\left(\boldsymbol{S}_{1}+\boldsymbol{S}_{2}+\cdots+\right.$ $\boldsymbol{S}_{m}$ ) dan $|\overline{\boldsymbol{S}}|$ merupakan determinan dari rata-rata matriks varian-kovarian yang memiliki distribusi

$$
|\overline{\boldsymbol{S}}| \sim \frac{|\boldsymbol{\Sigma}|}{[m(n-1)]^{p}} \prod_{k=1}^{p} \boldsymbol{V}_{\boldsymbol{k}} \text { dengan } \mathbf{V}_{\mathbf{k}} \sim \chi_{m(n-1)-k+1}^{2}
$$

Parameter $\boldsymbol{\Sigma}$ dapat ditaksir berdasarkan persamaan berikut:

dan

$$
\begin{gathered}
E(|\overline{\boldsymbol{S}}|)=E\left(\frac{|\boldsymbol{\Sigma}|}{[m(n-1)]^{p}} \prod_{k=1}^{p} \boldsymbol{V}_{\boldsymbol{k}}\right) \\
\quad=\frac{|\boldsymbol{\Sigma}|}{[m(n-1)]^{p}} \prod_{k=1}^{p} m(n-1)-k+1
\end{gathered}
$$

$$
\begin{aligned}
\operatorname{Var}(|\overline{\boldsymbol{S}}|)= & \left(\frac{|\Sigma|^{2}}{[m(n-1)]^{2 p}}\right) \prod_{k=1}^{p}[m(n-1)-k+1] \times\left[\prod_{j=1}^{p}[m(n-1)-j+3]-\prod_{i=1}^{p}[m(n-\right. \\
& 1)-i+1]]
\end{aligned}
$$

sehingga diperoleh $E(|\boldsymbol{S}|)=b_{3}|\boldsymbol{\Sigma}|$ dan $\operatorname{Var}(|\boldsymbol{S}|)=b_{4}|\boldsymbol{\Sigma}|^{2}$. Oleh karena itu, dalam hal ini $\frac{|\boldsymbol{S}|}{b_{3}}$ dan $\frac{|\boldsymbol{S}|^{2}}{\left({b_{3}}^{2}+b_{4}\right)}$ merupakan estimator tak bias dari $|\boldsymbol{\Sigma}|$ dan $|\boldsymbol{\Sigma}|^{2}$, dengan

$$
\begin{gathered}
b_{3}=\frac{1}{[m(n-1)]^{p}} \prod_{k=1}^{p} m(n-1)-k+1 \\
b_{4}=\frac{1}{[m(n-1)]^{2 p}} \prod_{k=1}^{p}[m(n-1)-k+1] \times\left[\prod_{j=1}^{p}[m(n-1)-j+3]-\prod_{i=1}^{p}[m(n-\right. \\
1)-i+1]]
\end{gathered}
$$

Diagram kontrol Improved Generalized Variance memiliki dua batas kontrol, yaitu Batas Pengendali Atas (BPA) dan Batas Pengendali Bawah (BPB) serta satu Garis Tengah (GT) yang berarti rata-rata proses. Proses dikatakan tidak terkontrol (out of control) apabila terdapat pengamatan yang keluar dari batas kontrol, titik-titik pengamatan tersebar secara sistematik atau tidak random, dan terdapat titik yang berturut-turut mengalami kenaikan atau penurunan. Adapun batas kontrol untuk diagram kontrol Improved Generalized Variance adalah sebagai berikut:

$$
\begin{gathered}
B P A=|\overline{\boldsymbol{S}}|\left(\frac{b_{1}}{b_{3}}+3 \sqrt{\frac{b_{2}}{b_{3}^{2}+b_{4}}}\right) \\
G T=|\overline{\boldsymbol{S}}| \frac{b_{1}}{b_{3}}
\end{gathered}
$$




$$
B P B=\max \left(0,|\overline{\boldsymbol{S}}|\left(\frac{b_{1}}{b_{3}}-3 \sqrt{\frac{b_{2}}{b_{3}^{2}+b_{4}}}\right)\right)
$$

\subsection{Analisis Kapabilitas Proses}

Kapabilitas proses merupakan suatu ukuran kinerja kritis yang menunjukkan proses mampu menghasilkan sesuai dengan spesifikasi produk yang diterapkan oleh manajemen berdasarkan kebutuhan dan ekspektasi pelanggan ${ }^{[3]}$. Indeks kapabilitas univariat yang dapat digunakan yaitu $\mathrm{C}_{\mathrm{pm}}$ dan $\mathrm{C}_{\mathrm{pmk}}$. Syarat yang harus dipenuhi sebelum melakukan perhitungan indeks kapabilitas $\mathrm{C}_{\mathrm{pm}}$ adalah data pengamatan berdistribusi normal, proses produksi dalam keadaan terkendali dan simetris. perhitungan indeks kapabilitas $\mathrm{C}_{\mathrm{pm}}$ dan $\mathrm{C}_{\mathrm{pmk}}$ untuk data univariat adalah sebagai berikut:

$$
\begin{gathered}
C_{p m}\left(Z_{k}\right)=\frac{U S L_{Z_{k}}-L S L_{Z_{k}}}{\sqrt[6]{\sigma_{Z_{k}}^{2}+\left(\mu_{Z_{k}}-T_{Z_{k}}\right)^{2}}} \\
C_{p m k}\left(Z_{k}\right)=\min \left\{\frac{U S L_{Z_{k}}-\mu_{Z_{k}}}{\sqrt[3]{\sigma_{Z_{k}}^{2}+\left(\mu_{Z_{k}}-T_{Z_{k}}\right)^{2}}}, \frac{\mu_{Z_{k}}-L S L_{Z_{k}}}{\sqrt[3]{\sigma_{Z_{k}}^{2}+\left(\mu_{Z_{k}}-T_{Z_{k}}\right)^{2}}}\right\}
\end{gathered}
$$

Perhitungan $\mathrm{C}_{\mathrm{pm}}$ dikatakan capable atau kinerja prosesnya sesuai dengan standar jika menghasilkan nilai yang berada pada batas $1 \leq \mathrm{C}_{\mathrm{pm}}<1,33$. Apabila nilai indeks kaabilitas yang dihasilkan $C_{\mathrm{pm}} \geq 1,33$ maka dapat dikatakan bahwa proses produksi cukup memuaskan. Dalam penelitian ini terdapat dua karakteristik kualitas sehingga indeks kapabilitas yang cocok digunakan dalam kasus ini adalah indeks kapabilitas multivariat yang didefinisikan dengan $\mathrm{MC}_{\mathrm{pm}}$ dan $\mathrm{MC}_{\mathrm{pmk}}$. Dalam menghitung nilai indeks kapabilitas multivariat digunakan pembobot dari masing-masing kapabilitas karakteristik kualitas yang ditetapkan oleh perusahaan. Jika tidak ada pembobotan untuk masing-masing kapabilitas karakteristik kualitas, maka nilai pembobot dianggap sama. Perhitungannya adalah sebagai berikut:

$$
\begin{gathered}
M C_{p m}\left(Z_{k}\right)=\sum_{k=1}^{p} W_{k} C_{p m}\left(Z_{k}\right) \\
M C_{p m k}\left(Z_{k}\right)=\sum_{k=1}^{p} W_{k} C_{p m k}\left(Z_{k}\right)
\end{gathered}
$$

dimana $\mathrm{MC}_{\mathrm{pm}}$ dan $\mathrm{MC}_{\mathrm{pmk}}$ berturut-turut merupakan $\mathrm{C}_{\mathrm{pm}}$ dan $\mathrm{C}_{\mathrm{pmk}}$ multivariat dengan pembobot $\mathrm{W}_{\mathrm{k}}$. $\mathrm{W}_{\mathrm{k}}$ merupakan pembobot berdasarkan kepentingan dari masing-masing karakteristik kualitas dengan $\sum_{k=1}^{p} W_{k}=1$.

\section{METODOLOGI PENELITIAN}

\subsection{Jenis dan Sumber Data}

Jenis data yang digunakan adalah data kuantitatif. Data yang digunakan merupakan data primer yang diperoleh di UD. Tegel K Kabupaten Wonogiri. Sampel yang digunakan dalam penelitian ini merupakan karakteristik kualitas yang berupa ketebalan dan berat paving block segienam yang diambil pada tanggal 26 November sampai dengan 15 Desember 2018. Dalam penelitian ini diambil data dengan 20 subgrup dan masing-masing subgrup terdiri dari 5 observasi, sehingga data yang ada berjumlah 100 .

\subsection{Variabel Penelitian}

Variabel penelitian yang digunakan untuk karakteristik kualitas paving block segienam adalah:

$\mathrm{X}_{1}$ : Ketebalan dengan satuan milimeter $(\mathrm{mm})$

$\mathrm{X}_{2}$ : Berat dengan satuan kilogram $(\mathrm{kg})$ 


\subsection{Metode Pengumpulan Data}

Data yang digunakan dalam penelitian ini merupakan data primer yang diperoleh dari UD. Tegel K Kabupaten Wonogiri. Sampel diambil secara acak dengan melakukan pengukuran secara langsung terhadap ketebalan serta berat paving block segienam yang dilakukan pada tanggal 26 November sampai dengan 15 Desember 2018.

\subsection{Teknik Analisis Data}

Teknik analisis data yang dilakukan dalam penelitian ini adalah sebagai berikut:

1. Mengumpulkan data primer yang berupa ketebalan serta berat paving block segienam yang diambil di UD. Tegel K Kabupaten Wonogiri.

2. Melakukan analisis deskriptif data karakteristik kualitas paving block segienam.

3. Melakukan pengujian distribusi normal multivariat terhadap variabel penelitian.

4. Melakukan pengujian korelasi antar variabel penelitian.

5. Melakukan standarisasi terhadap data ketebalan dan berat paving block segienam.

6. Membuat diagram kontrol Improved Generalized Variance.

a. Menghitung matriks varian-kovarian $\mathbf{S}_{\mathbf{i}}$ dari tiap subgrup.

b. Menghitung nilai determinan dari matriks varian-kovarian tiap subgrup.

c. Menghitung nilai $b_{1}, b_{2}, b_{3}$ dan $b_{4}$

d. Menghitung nilai BKA, GT dan BKB.

e. Membuat plot Improved Generalized Variance dengan batas kendali yang telah ditentukan.

7. Menghitung kapabilitas proses.

8. Melakukan penarikan kesimpulan dari hasil analisis. 


\section{HASIL DAN PEMBAHASAN}

\subsection{Deskripsi Data}

Karakteristik kualitas yang diamati dalam penelitian ini adalah ketebalan dan berat dari paving block segienam. Deskripsi data karakteristik kualitas paving block segienam diberikan pada Tabel 2.

Tabel 2. Deskripsi Karakteristik Kualitas

\begin{tabular}{lcccccc}
\hline Variabel & Mean & Modus & Varian & St. Dev & Minimum & Maksimum \\
\hline Ketebalan & 60,39 & 60,00 & 0,68475 & 0,82749 & 59,00 & 63,00 \\
Berat & 4,24 & 4,20 & 0,00466 & 0,06829 & 4,10 & 4,40 \\
\hline
\end{tabular}

Karena satuan ukur dari data karakteristik kualitas paving block segienam berbeda, maka dalam penerapan diagram kontrol Improved Generalized Variance data tersebut perlu dilakukan standarisasi dengan mengubahnya ke dalam bentuk z-score. Deskripsi data karakteristik kualitas paving block segienam yang telah distandarisasi dapat dilihat pada Tabel 3.

Tabel 3. Deskripsi Data Standarisasi Karakteristik Kualitas

\begin{tabular}{lccccc}
\hline Variabel & Mean & Varian & St. Dev & Minimum & Maksimum \\
\hline Ketebalan & $-9,25149 \mathrm{E}-15$ & 1 & 1 & $-1,67977$ & 3,15410 \\
Berat & $7,97140 \mathrm{E}-15$ & 1 & 1 & $-2,03258$ & 2,36061 \\
\hline
\end{tabular}

\subsection{Uji Asumsi Normal Multivariat}

Berdasarkan hasil perhitungan diperoleh nilai $b=58$ yang berarti lebih besar dari $50 \%$ dari banyaknya data observasi sehingga dapat disimpulkan bahwa data karakteristik kualitas paving block segienam berdistribusi normal multivariat. Dilihat dari output pada Gambar 1 menunjukkan bahwa plot cenderung mengikuti pola garis lurus sehingga dapat dikatakan data berdistribusi normal multivariat.

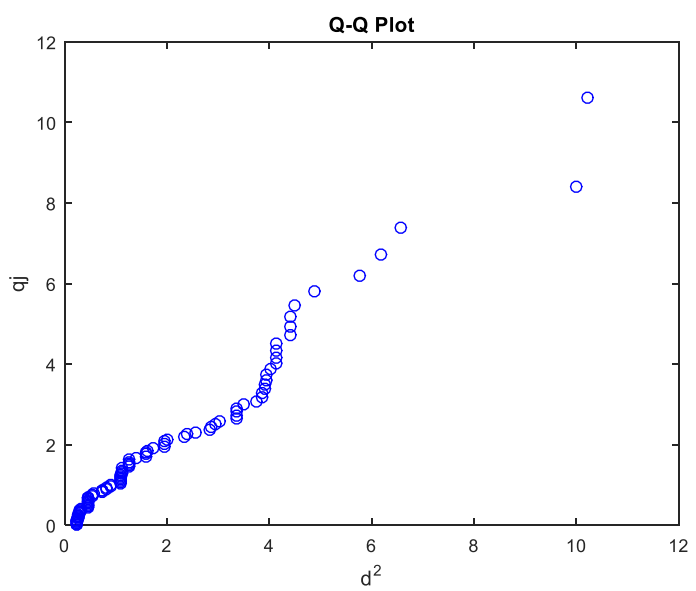

Gambar 1. Plot Normal Multivariat dengan Software Matlab

\subsection{Uji Korelasi Antar Variabel}

Untuk mengetahui korelasi antar variabel diperlukan matriks $\mathbf{R}$ yang akan dibandingkan dengan matriks identitas. Berikut adalah matriks $\mathbf{R}$ yang diperoleh:

$$
\boldsymbol{R}=\left[\begin{array}{cc}
1 & 0,2121 \\
0,2121 & 1
\end{array}\right]
$$

Berdasarkan perhitungan diperoleh nilai $\chi^{2}$ hitung sebesar $4,4899>\chi_{[0,05 ; 1]}^{2}$ sebesar 3,8415 dan $p$-value sebesar $0,0341<\alpha$ sebesar 0,05 sehingga dapat disimpulkan bahwa terdapat korelasi antara karakteristik kualitas ketebalan dan berat paving block segienam di UD. Tegel K Kabupaten Wonogiri. 


\subsection{Pengendalian Kualitas pada Variabilitas Proses Produksi Paving Block Segienam}

Berikut ini merupakan hasil pengendalian variabilitas proses produksi paving block segienam dengan menggunakan diagram kontrol Improved Generalized Variance yang terdapat pada Gambar 2.

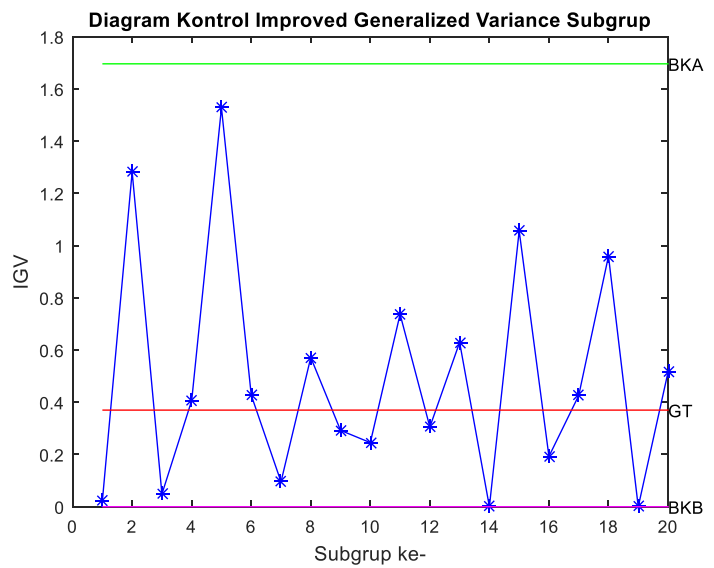

Gambar 2. Diagram Kontrol Improved Generalized Variance

Berdasarkan Gambar 2 terlihat bahwa proses produksi paving block segienam telah terkendali secara statistika. Hal tersebut terlihat dari plot-plotnya yang berada diantara Batas Pengendali Atas (BPA) sebesar 1,6960 dan Batas Pengendali Bawah (BPB) sebesar 0.

\subsection{Analisis Kapabilitas Proses Produksi Paving Block Segienam}

Indeks kapabilitas yang digunakan untuk mengukur kapabilitas proses dalam penelitian ini adalah $\mathrm{C}_{\mathrm{pm}}$ dan $\mathrm{C}_{\mathrm{pmk}}$. Indeks $\mathrm{C}_{\mathrm{pm}}$ dapat digunakan jika datanya simetris atau mean proses tepat berada di tengah batas spesifikasi. Apabila terdapat kemencengan maka digunakan indeks $\mathrm{C}_{\mathrm{pmk}}$. Suatu proses dapat dikatakan baik apabila nilai indeks yang dihasilkan berada dalam batas $1 \leq \mathrm{C}_{\mathrm{pm}}<1,33$. Jika nilai indeks yang dihasilkan $\mathrm{C}_{\mathrm{pm}} \geq 1,33$ maka dapat dikatakan bahwa proses produksi cukup memuaskan.

Berikut merupakan batas spesifikasi bawah dan batas spesifikasi atas untuk tiap karakteristik kualitas ketebalan dan berat paving block segienam yang digunakan oleh UD. Tegel K Kabupaten Wonogiri yang dapat dilihat pada Tabel 4.

Tabel 4. Batas Spesifikasi Karakteristik Kualitas

\begin{tabular}{cccc}
\hline Variabel & $\begin{array}{c}\text { Batas } \\
\text { Spesifikasi } \\
\text { Bawah }\end{array}$ & $\begin{array}{c}\text { Batas } \\
\text { Spesifikasi } \\
\text { Atas }\end{array}$ & Target \\
\hline Ketebalan & $55 \mathrm{~mm}$ & $65 \mathrm{~mm}$ & $60 \mathrm{~mm}$ \\
\hline Berat & $4,0 \mathrm{~kg}$ & $4,5 \mathrm{~kg}$ & $4,0 \mathrm{~kg}$ \\
\hline
\end{tabular}

Nilai tersebut terlebih dahulu diubah ke dalam bentuk z-score. Adapun hasil standarisasi untuk nilai batas spesifikasi atas, batas spesifikasi bawah, dan target untuk masing-masing karakteristik kualitas dapat dilihat pada Tabel 5. 
Tabel 5. Nilai Standarisasi Batas Spesifikasi dan Target Tiap Karakteristik Kualitas

\begin{tabular}{cccc}
\hline Variabel & $\begin{array}{c}\text { Batas } \\
\text { Spesifikasi } \\
\text { Bawah }\end{array}$ & $\begin{array}{c}\text { Batas } \\
\text { Spesifikasi } \\
\text { Atas }\end{array}$ & Target \\
\hline Ketebalan & $-6,51364$ & 5,57103 & $-0,47130$ \\
\hline Berat & $-3,49698$ & 3,82500 & $-3,49698$ \\
\hline
\end{tabular}

Perhitungan indeks kapabilitas proses secara univariat untuk karakteristik kualitas ketebalan paving block segienam diperoleh nilai $C_{\mathrm{pm}}$ dan $\mathrm{C}_{\mathrm{pmk}}$ sebesar 1,82190 dan 1,67980. Sedangkan indeks kapabilitas proses secara univariat untuk karakteristik kualitas berat paving block segienam diperoleh nilai $\mathrm{C}_{\mathrm{pm}}$ dan $\mathrm{C}_{\mathrm{pmk}}$ sebesar 0,33552 dan 0,35055. Karena nilai indeks $\mathrm{C}_{\mathrm{pm}}$ tidak sama dengan $\mathrm{C}_{\mathrm{pmk}}$ pada kedua karakteristik kualitas di atas maka dapat dikatakan bahwa mean proses tidak tepat berada di tengah batas spesifikasi sehingga dapat disimpulkan terdapat kemencengan. Karena proses tidak simetris atau terdapat kemencengan, maka dalam pengambilan kesimpulan digunakan indeks $\mathrm{C}_{\mathrm{pmk}}$.

Berdasarkan nilai indeks $\mathrm{C}_{\mathrm{pmk}}$ maka dapat dihitung nilai indeks kapabilitas multivariat $\mathrm{MC}_{\mathrm{pmk}}$. Untuk mencari nilai indeks multivariat diperlukan nilai pembobot untuk masingmasing karakteristik kualitas. Dalam proses produksi paving block segienam ini pihak pabrik menganggap bahwa kedua karakteristik kualitas, yaitu ketebalan serta berat memiliki peran yang sama pentingnya dalam mempengaruhi proses sehingga nilai pembobot yang digunakan dianggap sama, yaitu 0,5. Adapun nilai indeks $\mathrm{MC}_{\mathrm{pmk}}$ yang diperoleh sebesar 1,01517 yang berarti bahwa secara multivariat kinerja proses produksi paving block segienam di UD. Tegel K Kabupaten Wonogiri sudah capable atau kinerja prosesnya berjalan sesuai dengan standar.

\section{KESIMPULAN}

Berdasarkan analisis dan pembahasan yang diperoleh pada bab sebelumnya, dapat disimpulkan bahwa diagram kontrol Improved Generalized Variance merupakan salah satu alat untuk mengontrol variabilitas proses produksi. Penerapan diagram kontrol Improved Generalized Variance pada data karakteristik kualitas proses produksi paving block segienam di UD. Tegel K Kabupaten Wonogiri menunjukkan bahwa plot-plot berada diantara Batas Pengendali Atas (BPA) dan Batas Pengendali Bawah (BPB) yaitu sebesar 1,6960 dan 0. Hal tersebut berarti bahwa variabilitas proses produksi paving block segienam telah terkendali secara statistika. Nilai kapabilitas proses multivariat yang dihasilkan yaitu 1,01517, sehingga dapat disimpulkan bahwa kapabilitas proses multivariat pada proses produksi paving block segienam sudah capable atau kinerja prosesnya berjalan sesuai dengan standar.

\section{DAFTAR PUSTAKA}

[1] Assauri, S. 2004. Manajemen Produksi dan Operasi. Jakarta: Lembaga Penerbit Fakultas Ekonomi Universitas Indonesia.

[2] Djauhari, M.A. 2005. Improved Monitoring of Multivariate Process Variability. Journal of Quality Technology, Vol. 37, No. 1.

[3] Gaspersz, V. 2002. Pedoman Implementasi Program Six Sigma Terintegrasi dengan ISO 9001:2000, MBNQA, dan HACCP. Jakarta: PT Gramedia Pustaka Utama.

[4] Johnson, R.A. dan D.W. Wichern. 2007. Applied Multivariate Statistical Analysis Sixth Edition. United States of America: Pearson Education.

[5] Montgomery, D.C. 2012. Introduction to Statistical Quality Control Seventh Edition. United States of America: John Wiley \& Sons, Inc. 
[6] Morrison, D. 1990. Multivariate Statistical Methods (Third Edition). New York: Mc Graw Hill Publishing Company.

[7] SNI. 1996. Standar Nasional Indonesia 03-0691-1996, tentang Bata Beton (Paving Block). Badan Standardisasi Nasional. 